\title{
Standardization and contextualization: A study of language and leadership across 17 countries $^{2 / 2}$
}

\author{
Lena Zander $^{\mathrm{a}, 1, *}$, Audra I. Mockaitis ${ }^{\mathrm{b}}$, Anne-Wil Harzing ${ }^{\mathrm{c}}$
}

Joyce Baldueza, Worldbank, Philippines; Wilhelm Barner-Rasmussen, Hanken School of Economics, Finland; Cordula Barzantny, Groupe ESC Toulouse Business School, France; Anne Canabal, University of Maine, USA; Anabella Davila, Graduate School of Business Administration and Leadership, Tecnologico de Monterrey, Mexico; Alvaro Espejo, School of Business, Universidad Adolfo Ibañez, Chile;

Rita Fernandes Ferreira, Universidade Católica Portuguesa, Portugal and IESE Business School, Spain; Axéle Giroud, Manchester Business School, UK; Kathrin Koester, University of Heilbronn, Germany; Yung-Kuei Liang, Tatung University, Taiwan; Michael J. Morley, Kemmy Business School, University of Limerick, Ireland; Barbara Myloni, University of Patras, Greece; Joseph O.T. Odusanya, HayGroup SA, South Africa; Sharon Leiba O'Sullivan, Telfer School of Management, University of Ottawa, Canada; Ananda Kumar Palaniappan, University of Malaya, Malaysia; Paulo Prochno, Robert H. Smith School of Business, University of Maryland, USA; Srabani Roy Choudhury, Jawaharlal Nehru University, India; Ayse Saka-Helmhout, University of Surrey, UK; Sununta Siengthai, Asian Institute of Technology, Thailand; Ayda Uzuncarsili Soydas, Marmara University, Turkey; Linda Viswat, Otemon Gakuin University, Japan.

\footnotetext{
a Uppsala University, Sweden

${ }^{\mathrm{b}}$ Victoria University of Wellington, New Zealand

${ }^{\mathrm{C}}$ University of Melbourne, Australia
}

\section{A R T I C L E I N F O}

Article history:

Available online 30 August 2010

\section{Keywords:}

Language

Leadership

Context

Culture

Multinational company

Cultural accommodation

\begin{abstract}
A B S T R A C T
With multinational corporations increasingly adopting English as a corporate language, the issue of language management and the pros and cons of language standardization have been widely debated in the literature. Our 17-country study considers whether the use of English as a common corporate language causes difficulties. We empirically examine whether managerial reactions to specific leadership scenario-based situations change as a consequence of the language they use. Our results show that the choice of language (native or English) does not matter much for the studied leadership scenarios. Instead, leadership decisions and reactions depend more on cultural and situational context.
\end{abstract}

(c) 2010 Elsevier Inc. All rights reserved. the authors wish to thank the JWB Special Issue editors Rebecca Piekkari and Susanne Tietze, and the three anonymous reviewers for their insightful comments. An earlier version of this paper entitled 'Don't just say what you meanContextualize It: A Leadership Study across 17 Countries' was published in the 2009 Academy of Management Best Paper Proceedings and was a finalist for the International Management Division Best Paper in OB/HRM/OT. It was also nominated by the International Management Division for the Carolyn Dexter Award. Comments from conference participants and anonymous reviewers are gratefully acknowledged.

* Corresponding author. Tel.: +4618471 1239.

E-mail addresses: lena.zander@fek.uu.se (L. Zander), audra.mockaitis@vuw.ac.nz (A.I. Mockaitis), harzing@unimelb.edu.au (A.-W. Harzing).

${ }^{1}$ Country collaborators are listed alphabetically after the first three co-authors. Please note that this list indicates the collaborators' current affiliations, which are not always the universities at which the data were collected.

\section{Introduction}

"Siemens speaks several languages - despite what the management says," shouts the heading of a recent review in Human Resource Management International Digest (2007, p. 16). This review highlights the findings of Fredriksson, BarnerRasmussen and Piekkari (2006) that a common corporate language may not be widely shared by organizational members throughout the multinational company (MNC), regardless of corporate attempts to make the MNC monolingual. Fredriksson et al. (2006) also detected a strong tendency of convergence towards English in large parts of the organization, irrespective of the company's history and German roots. 
In recent years, the topic of language - its importance and influence on MNC strategy, human resource management policies, knowledge flows and communication, has gained prominence as a separate area of study with attention devoted to it in research by Marschan, Welch and Welch (1997), Marschan-Piekkari, Welch and Welch (1999a, 1999b), Feely and Harzing (2003), Piekkari, Vaara, Tienari, and Säntti (2005), Luo and Shenkar (2006), Harzing and Feely (2008) and others. There is a general consensus in the literature that language matters. Yet, we still know little about how firms cope with language issues (Maclean, 2006). Although researchers agree that MNCs need to manage linguistic diversity (see, e.g., Feely \& Harzing, 2003; Janssens, Lambert, \& Steyaert, 2004; Luo \& Shenkar, 2006), the pros and cons of a common corporate language strategy are still being debated, despite much of the early empirical evidence pointing towards substantial difficulties in achieving language standardization (Dhir \& GokePariola, 2002; Fredriksson et al., 2006; Piekkari et al., 2005; Marschan-Piekkari, Welch, \& Welch, 1999a). Yet for many people working in MNCs, communicating in English - the lingua franca of international business - is increasingly the operational reality.

What, then, does a multilingual context imply for managers working in multinational companies? Daily work encounters in the multilingual organization are carried out sequentially, or simultaneously, in two or more languages. Language skills surface as a critical managerial competence (Fredriksson et al., 2006). Linguistic differences create hurdles, hampering managers' coordination of activities, the development of strong relationships, and hindering successful performance (Griffith, 2002). Such difficulties are akin to those posed by cross-cultural encounters. The notion that language and culture are closely intertwined implies that individuals think and act differently depending on the language they are using (Ralston, Cunniff, \& Gustafson, 1995). Yet, despite increasing attempts at standardizing language in MNCs there seems to be limited knowledge about the managerial implications of working in English across national, linguistic, and cultural borders. This leads us to question whether the language used by managers and employees in leadership situations raises a serious concern when opting for a common corporate language as a solution to language management.

Our study seeks to bridge the gap between these two streams of language research - the role of language in international management, and the cross-cultural difficulties posed by language, by assessing if and when language matters for managers in a leadership situational context. We empirically test the effects of language on respondents' decisions regarding leadership scenarios in 17 countries by comparing differences in responses to both native language and English-language questionnaires. Previous research has revealed that respondents adjust their responses to questionnaires depending on the language of the research instrument (e.g., Harzing et al., 2005; Ralston, Cunniff, et al., 1995), suggesting that choice of language matters. Such studies examined responses to attitudinal statements. Our study takes a different approach. By asking respondents to consider specific situations or scenarios that may occur in the typical workplace and indicate how they would react to situations, respondents are placed in a frame of mind that allows them to interpret the situational context, not the language. Thus, if differences are revealed between language versions, this will indicate that language is, in fact, important regardless of the situation. However, if there are no language differences, then contextualization, or consideration of the situational context in making decisions, may be key to understanding the implications of working only in one's non-native language - English. We will also examine whether there are differences across countries. Identified cross-national differences in managers' reactions to specific leadership scenarios would suggest that the cultural, as well as the situational, contexts matters for leadership.
We structure our paper as follows. We begin with a brief review of the literature on language standardization in MNCs, and discuss cultural accommodation as a means for evaluating the role of language in organizations. We next introduce the design of our study and present the results, followed by a discussion of the findings, limitations and implications for managers in multilingual organizations.

\section{Theoretical background}

\subsection{A common corporate language - the standardization issue}

Although it is generally recognized that decisions about corporate language are an important consideration, much of the MNC literature has traditionally treated language issues as tangential to more tangible aspects of corporate strategy and human resources policy formulation (Piekkari et al., 2005). MNCs may choose to instill a common language throughout the organization on the foundation that it facilitates faster communication flows within the organization, in terms of formal and informal reporting mechanisms within individual units and between organizational units. This is believed to improve coordination, integration and inter-organizational learning (Luo \& Shenkar, 2006). A common language also fosters a sense of identity and helps shape corporate image, gives organizational members a sense of belonging (Marschan-Piekkari, Welch, \& Welch, 1999b), and avoids the hassles associated with operating in multiple languages.

Because of the acceptance of English as a dominant language in international business, many MNCs choose it as their common corporate language (Charles \& Marschan-Piekkari, 2002; Piekkari et al., 2005). An interesting case study conducted by Charles and Marschan-Piekkari (2002) in a Finnish MNC, revealed that choosing English as the company language in non-Anglo firms is not always the best solution. Their case firm reported difficulties in finding adequate numbers of employees sufficiently skilled in English to participate in meetings between units; thus employees often reverted to the parent company language.

Although the benefits of standardized communication within the organization are many, the implementation of a common language often English, is fraught with difficulties. Subsidiaries of MNCs in non English-speaking countries, for example, may be burdened with translation of policies, procedures and communication. Subsidiary managers, who are non-native speakers of English, may encounter difficulties in communicating across subsidiaries and with headquarters. Employees who lack language skills may not be invited to attend key meetings and be involved in decision-making (LouhialaSalminen, Charles, \& Kankaanranta, 2005). As Fredriksson et al. (2006) note, the adoption of a common language does not automatically improve employees' knowledge of it. To overcome this, firms may choose to fill key subsidiary positions with expatriates (Feely \& Harzing, 2003). This may be quite a costly, and not always successful, bridging strategy (Osland, 1995).

On the other hand, employees who are well versed in the common corporate language may experience preferential treatment, greater power, or fast-tracked career advancement, even if their technical skills are not up to par. They may, however, feel forced to assume the role of communication liaisons in a multitude of situations, also acting as gatekeepers, rather than focusing on their own tasks (Marschan-Piekkari, Welch, \& Welch, 1999a). The implications may be as far reaching as the emergence of 'shadow structures', identified by Marschan-Piekkari et al. (1999b), where language similarities glue subsidiaries together in communication networks that function independently from the main organization. Conversely, employees who have key competencies or knowledge but do not speak the language may be lost (Piekkari et al., 2005). 
Maclean (2006) points out that native-English speakers may also be at a disadvantage in cross-cultural interactions compared to non-native speakers, as their language use is embedded in their culture, whereas non-native speakers speak the language of international business. Charles and Marschan-Piekkari (2002) found too, that native-English speakers encounter difficulties even when the official corporate language is English because of the various "Englishes" spoken by people of different nationalities. Thus, although the use of English as a common corporate language has its benefits, these are counterbalanced by pitfalls that caution against it as a blanket solution for all situations. Naturally, this begs the question of when and how the MNC, or any international organization, should adopt one or another language strategy. The standardization question has largely been addressed from communication and power perspectives. We turn to a different stream of research, where the influence of culture is considered on language with respect to perceptions and preferences in the workplace. There is evidence in the literature that people's perceptions are, in fact, shaped by language. In making decisions about language strategy, research on cultural accommodation may thus provide managers with some clues as to what happens when individuals function in a foreign language.

\subsection{Language and cultural accommodation}

The notion that language and culture are closely intertwined was first introduced by Whorf (1956 in Politzer, 1991). Whorf argued that language influences the ways in which individuals think and perceive the world. Several researchers have attempted to test this assumption with a variety of approaches. One of these is the cultural accommodation hypothesis, which posits that individuals adjust their responses (or behaviors) in a way that corresponds to the culture with which they have an encounter (Ralston, Cunniff, et al., 1995). First coined by Yang and Bond (1980), cultural accommodation specifically suggests that individuals think and act differently depending on the language they are using (Ralston, Cunniff, et al., 1995). In many studies, cultural accommodation effects are tested with a research design using both English and native language versions of the same questionnaire, but they have also been tested in nonverbal interaction and interview settings (Bond \& Yang, 1982). Thus, when non-native speakers of English are presented with English-language questionnaires, it is expected that they will respond in ways more typical of native-English speakers than their own culture.

Harzing et al. (2002) identified eight studies that tested the cultural accommodation hypothesis. Generally, cultural accommodation was found in studies focusing on cultural values (Bond \& Yang, 1982; Botha, 1970; Earle, 1969; Ralston, Cunniff, et al., 1995; Tyson, Doctor, \& Mentis, 1988), but not in studies focusing on more neutral items (Candell \& Hulin, 1986; Hulin, Drasgow, \& Komocar, 1982; Katerberg, Smith, \& Hoy, 1977). A large-scale study conducted by Harzing et al. (2002) also revealed greater cultural accommodation for cultural value-laden than more neutral questions. Importantly, this study showed that cultural accommodation is also present for languages that are 'closer' to English, such as those stemming from the same Indo-European language tree.

Despite the assertion of Welch and Welch (2008) that functioning in a common corporate language that is not one's native language will create a disconnection between individuals and their own national cultural base, there is evidence suggesting that cultural and contextual (or situational) frames of reference are still drawn upon when using a foreign language. Watkins and Gerong (1999), for example, found no support for cultural accommodation in their study of Filipino school-aged respondents. They found evidence that some respondents were influenced by the situational context at school, rather than language. Yang and
Bond (1980) found that Chinese responded to English-language questionnaires in ways typical of their culture, suggesting that even when people communicate in a foreign language, they rely on their own cultural cues for direction.

Some studies have found evidence of cultural accommodation, while others have found that respondents revert to their culture or are influenced by the situation. In their 1982 study, Bond and Yang proposed that cultural accommodation exists when respondents are less committed to the questionnaire items. Conversely, the more important an attitude or value is to an individual, the more one reverts to one's own cultural frame of reference - the smaller the language effect. This may help to explain the conflicting findings of previous studies. To some extent the cultural accommodation literature provides clues regarding how individuals react when functioning in a foreign language. On the one hand, respondents display cultural accommodation when cultural value-laden questions are assessed in English. That is, Englishversion responses differ from native language responses, suggesting that language is a vehicle for culture-based attitudes. On the other hand, when something is perceived as important or refers to specific situations (e.g., Ralston, Terpstra, Cunniff, \& Gustafson, 1995) it is suggested that individuals take cues from their own culture. Thus, whether a common corporate language poses difficulties for individuals within the MNC may depend in part on the situational, or the cultural context, in which decisions or actions are made.

\subsection{Language standardization and contextualization: the research questions}

Our two-pronged review highlighted an apparent tension in the literature regarding the role of language in international management. The language standardization literature points to many advantages (from the organizational perspective) and disadvantages (from an employee perspective) of a common corporate language. The cultural accommodation literature, too, has shown that individuals may react more or less strongly to the language used. Although the literature stresses the disadvantages of language standardization, operating in multiple languages is impractical for most organizations (and most individuals). There is still a need to reconcile these divergent viewpoints in the literature and to advance the discussion towards one that considers whether the use of English as a corporate language has an effect on managers who work in their non-native language.

Research Question 1: Does the language in which people function have an influence on their decisions and actions in an organizational setting? Specifically, will managers' reactions within a leadership situation context differ depending on whether they are reacting in English or their native language?

In considering cultural accommodation and the theorized link between language and culture, we sought to delve deeper into language management issues. Studies within this field have found that individuals may adjust their way of thinking, and possibly their behavior, depending on the language that they are using. On the one hand, this may have a homogenizing effect, which could facilitate the use of a standardized language. On the other hand, if companies believe that cultural differences are a source of diversity in ideas that ultimately result in more superior solutions, then such a streamlining effect is less desirable.

We found that the findings of cultural accommodation studies were inconclusive regarding the relationship between language and culture-how both shape people's thinking and, in turn, their interactions. Cultural accommodation largely occurred in responses to questions measuring national cultural dimensions, 
Table 1

Sample characteristics.

\begin{tabular}{|c|c|c|c|c|c|c|c|c|c|c|c|}
\hline \multirow[t]{2}{*}{ Country } & \multicolumn{3}{|c|}{ Language version } & \multicolumn{2}{|c|}{ Gender (female) } & \multicolumn{2}{|l|}{ Age } & \multicolumn{2}{|c|}{$\begin{array}{l}\text { Work experience } \\
\text { (years) }\end{array}$} & \multicolumn{2}{|c|}{ Level of English ${ }^{a}$} \\
\hline & Local & English & Total & $n$ & $\%$ & Mean & S.D. & Mean & S.D. & Mean & S.D. \\
\hline Brazil & 59 & 58 & 117 & 44 & 37.6 & 34.62 & 6.84 & 13.40 & 7.00 & 2.36 & 1.18 \\
\hline Chile & 54 & 51 & 105 & 8 & 7.6 & 33.97 & 5.04 & 9.57 & 5.30 & 2.88 & 1.12 \\
\hline Finland & 40 & 32 & 72 & 19 & 26.4 & 37.19 & 5.83 & 13.44 & 6.34 & 1.61 & 0.87 \\
\hline Germany & 59 & 53 & 112 & 24 & 21.4 & 36.03 & 5.59 & 10.75 & 5.43 & 1.81 & 0.87 \\
\hline Greece & 44 & 53 & 97 & 51 & 52.6 & 32.19 & 6.31 & 8.60 & 5.74 & 2.33 & 1.19 \\
\hline India & 58 & 62 & 120 & 24 & 20.0 & 24.95 & 2.70 & 2.27 & 2.81 & 1.08 & 0.36 \\
\hline Japan & 62 & 22 & 84 & 17 & 20.2 & 27.06 & 8.12 & 3.22 & 7.47 & 2.91 & 1.11 \\
\hline Lithuania & 52 & 55 & 107 & 78 & 72.9 & 25.19 & 3.68 & 3.86 & 3.67 & 2.96 & 1.05 \\
\hline Malaysia & 53 & 45 & 98 & 55 & 56.1 & 31.09 & 5.36 & 7.26 & 4.62 & 1.18 & 0.54 \\
\hline Mexico & 84 & 84 & 168 & 48 & 28.6 & 28.82 & 4.37 & 7.11 & 4.96 & 1.96 & 0.99 \\
\hline Netherlands & 45 & 67 & 112 & 30 & 26.8 & 38.61 & 6.82 & 15.92 & 7.49 & 2.45 & 0.98 \\
\hline Philippines & 22 & 22 & 44 & 27 & 61.4 & 29.48 & 5.87 & 7.76 & 5.44 & 1.30 & 0.67 \\
\hline Portugal & 60 & 47 & 107 & 20 & 18.7 & 33.47 & 5.94 & 10.41 & 5.99 & 2.01 & 1.16 \\
\hline Sweden & 46 & 50 & 96 & 25 & 26.0 & 37.55 & 5.81 & 14.43 & 6.43 & 1.92 & 0.98 \\
\hline Thailand & 57 & 64 & 121 & 71 & 58.7 & 32.30 & 8.91 & 9.45 & 8.18 & 1.90 & 0.93 \\
\hline Taiwan & 53 & 46 & 99 & 45 & 45.5 & 34.35 & 7.79 & 9.19 & 6.68 & 2.64 & 1.15 \\
\hline Turkey & 58 & 59 & 117 & 51 & 43.6 & 28.03 & 4.06 & 5.84 & 4.48 & 2.38 & 1.11 \\
\hline Total & 906 & 870 & 1776 & 637 & 35.9 & 31.92 & 7.24 & 8.95 & 6.99 & 2.09 & 1.12 \\
\hline
\end{tabular}

a 1 = daily and $4=$ once per month or less.

or culture value-laden questions in one's non-native language. However, cultural accommodation was not detected, for the most part, for questions that were viewed as 'important' or to which respondents were more committed. This raises questions as to what happens when respondents consider issues that are both value-laden and perceived as critical to their activities, for example, when managers must react in English (or another nonnative language) to a situation that is culture-endorsed and to which they are committed.

Research Question 2: How important is cultural context in the language debate? Specifically, will managers' reactions to specific leadership situations differ across countries, regardless of whether they are reacting in English or their native language?

Our overall objective in this study is thus to cast some light on the implications of a common corporate language for managers working in multilingual organizations and for multinational organizations opting for language standardization. We will specifically examine if and when language influences the ways in which managers respond to different leadership situations in the workplace. By providing specific situations and asking respondents to decide on a course of action from several alternatives, we expect language effects to be better revealed and isolated; an assessment of scenario-based leadership decisions will reveal whether the situational context or the language in which people function influences choices. If strong language effects are found, the implications of standardization are of concern. Further, the large cross-national design of our study allows us to test whether people tap into national frames of reference when making leadership decisions in a cultural context.

\section{Method}

\subsection{Sample and data collection procedure}

The data for this study were collected in 17 countries. $^{2}$ Respondents were participants in post-graduate executive educa-

\footnotetext{
${ }^{2}$ Data was originally collected in 22 countries, however, five countries were excluded from this study either because their native language was English (Canada, Ireland, UK, USA) or, in the case of France, because of outliers in the sample for the English language version.
}

tion or MBA programs at major universities. In all countries participants had prior working experience - a grand mean of 8.95 years of work experience (see Table 1 ). We purposefully sampled respondents with work experience, so that in their responses to our survey they could draw on real life experiences. This mitigates the traditional disadvantages of experimental designs. In most countries the mean age of respondents was in the low to mid 30s, with exceptions in India, Japan, Lithuania, Mexico, Philippines and Turkey, where the mean age was under 30 . Not surprisingly, the countries with the youngest samples also had less work experience. The mean country sample size was 104.5; a few countries had unusually large or small samples. The largest sample was obtained in Mexico $(N=168)$, and the sample was rather small $(N=44)$ in the Philippines.

In each country, half of the respondents completed questionnaires in English and half in their native language; the language versions were distributed randomly, most often to participants in the same course. To ensure randomness respondents were not able to choose which language version they completed; most often they were not aware that there were different language versions. To verify whether collaborators had succeeded in the randomisation process, we tested whether the two language groups differed on one of the background questions: "How similar are your norms and values to the majority of people in your birth country?" None of the countries in the study showed a significant difference between the language versions on this question. The distribution of questionnaires was random.

\subsection{Research instrument and development of scenarios}

The questionnaire contains two sets of questions. The first part contains leadership scenarios that were specifically developed in this project and represent an innovative approach for studying leadership within and across countries. For each scenario, respondents were asked to put themselves in the position of a manager (e.g., product division manager, CEO, top manager, department manager) of a company in one's home country and to rank their top three alternatives regarding how they would behave. Each scenario pertained to a different aspect of leadership. A choice of six to eight alternative actions for each scenario was provided.

Scenario 1 pertains to the manager's response to Rewarding individuals or teams. In Scenario 2, Decision-making, the respondents need to assess how one would make an important decision as 
CEO of a company. Scenario 3, Goal-setting, asks the respondents to rank their main priorities as a top manager. Scenario 4, Face-saving, gauges respondents' behaviors as a manager with technical expertise faced with a situation in which their superior has just made a mistake in presenting the company's product to clients. Scenario 5, Conflict-resolving, deals with a manager's response to inter-departmental conflict. Scenario 6, Empathizing, refers to respondents' reactions to personal difficulties encountered by a direct subordinate.

The second part of the questionnaire contained several demographic questions, such as age, gender, work experience, and level of language knowledge, as well as questions about the ideal type of job that respondents preferred. Several questions to assess nationality (country of birth, the country with which one identifies the most and how typical one's views are of one's country of birth) also ensured that only nationals were included in the data-analysis, and to further confirm that the distribution of the two language versions of the questionnaire was random.

\subsection{Development and translation of the questionnaire}

The procedure used in developing and subsequently translating our questionnaire is a combined decentering and committee translation method (Brislin, 1980; Candell \& Hulin, 1986; Nasser, 2005). Decentering has been lauded as a sound technique in developing cross-national research instruments (Green \& White, 1976), while committee translation takes this a step further. The scenarios and their choice alternatives were developed in three rounds of focus groups, each including 6 MBA or Ph.D. students of different nationalities. The project coordinator conducted a first discussion in English with 6 students from different nationalities and asked the broad question: "What types of management issues are important in your country?" This topic was discussed intensively for approximately two hours. The project coordinator then constructed the scenarios based on the outcome of the focus group discussion. During a second 2-hour session with the original focus group, the scenarios were fine-tuned, and in some cases the range of alternative choices was expanded. A second group of students (equally diverse) then checked the scenarios for comprehensibility and logic. In this stage only minor changes were made.

The questionnaires were next translated by bilingual research assistants under the supervision of the project coordinator. The translated version was subsequently discussed in a focus group including both the translator and two or three other bilingual students in the presence of the project coordinator. The other students were instructed to read the translated instrument sentence by sentence and indicate whether the text sounded natural to them. Subsequently, they were instructed to look at the original English sentence and assess its equivalence to the native version. If the sentences were not felt to be fully equivalent, a better translation was sought through discussion between the participants. Where necessary, the project coordinator provided feedback on the meaning behind the questions. This process took at least three hours, but for some languages (e.g. Japanese, Chinese) it took several sessions lasting up to eight hours in total. In addition, country collaborators verified the surveys for accuracy of translation and for potential local language differences, e.g. the different variants of Spanish used in Latin American countries.

\subsection{Measures}

\subsubsection{Dependent variables}

Our dependent variables pertain to the six leadership scenarios. We have included those scenario alternatives that were selected as a first choice by the majority of respondents in each country. Because these varied across countries, more than one alternative is chosen for each scenario (see Table 2 for the phrasing of the scenarios and the corresponding choice alternatives). For each scenario alternative, a score was assigned by each respondent, expressed on a ranking scale of $1-3$, where 1 corresponds to a higher ranking and 3 to a lower ranking for the alternative. Alternatives not selected among the top three choices were scored with 0 .

\subsubsection{Independent variables}

Two independent variables are employed in this study. The Language of the questionnaire was a dichotomous variable, where $0=$ native and $1=$ English; Country was included as a nominal variable.

\subsubsection{Control variables}

As our scenarios ask respondents to respond as though they are the managers described in each scenario, respondents' perceptions of the given scenarios may be influenced not only by the language version of their questionnaire but also by their personal backgrounds. We examine these attributes with the following variables: Age (in years) and Gender $(1=$ female, $0=$ male), Level of English, measured as the frequency of reading English as a foreign language (as opposed to the more common use of selfassessed knowledge) on a 4-point scale, where $1=$ daily and 4 = once per month or less, and Work experience, measured as the total number of years of work experience.

\section{Results}

We selected only those scenario alternatives that were chosen by a majority of respondents within each country. Although there were 6-8 alternatives for each scenario, many of them were not chosen as first choice alternatives by any respondents or only a very small percentage of respondents in the majority of countries. These were excluded from further analysis, leaving us with 15 alternative choices to examine (see Table 3 ).

Our first statistical analysis, addressing research question 1 , was conducted to test for the effect of language across all countries on the choice of leadership scenario alternatives. Following a procedure suggested by Van de Vijver and Leung (1997), the effect of language in the presence of other variables is isolated. An ANOVA was first conducted to test the effect of language on the dependent variables $\left(F_{1}\right)$. Next, the demographic variables were entered as covariates and an $F_{2}$ value was obtained for the language effect. Where $F_{1}$ and $F_{2}$ do not differ significantly, differences in the first set of dependent variables cannot be accounted for by the covariates. Where $F_{1}$ is significant, but $F_{2}$ is smaller yet significant as well, the covariates provide a partial explanation of the dependent variable. If $F_{2}$ is no longer significant after the inclusion of the covariates, the dependent variable is entirely explained by the covariates, i.e., age, gender, work experience or level of English.

Table 3 depicts the results for the leadership scenario alternatives. After controlling for demographic variables, the language effect was persistent for only two of the 15 scenario alternatives, the Rewarding scenario (alternative: group reward) and the Decision-making scenario (alternative: consult employees and announce). A significant language effect also appears after the introduction of covariates in two alternatives for the Face-saving scenario (alternatives: mention correct features in meeting and politely correct in meeting).

In our second statistical analysis addressing research question 2, we used the General Linear Model procedure to test for country effects. We split our data file into two groups according to the language of the questionnaire (native versus English), and included country as the independent variable and our demographic 
Table 2

Scenarios and response alternatives.

\begin{tabular}{|c|c|}
\hline Scenario 1: Rewarding & Scenario 2: Decision-making \\
\hline $\begin{array}{l}\text { You are a manager of a product division that } \\
\text { includes several workplace teams. In your } \\
\text { opinion what would be the best way to } \\
\text { reward high performing employees in this } \\
\text { division? }\end{array}$ & $\begin{array}{l}\text { You are a company CEO and need to make a major } \\
\text { decision that will have an impact on all employees. } \\
\text { In your opinion, what would be the best way to } \\
\text { make this decision? }\end{array}$ \\
\hline $\begin{array}{l}\text { S1-1. Individual financial incentive based on } \\
\text { each employee's individual performance } \\
\text { (individual reward) }\end{array}$ & $\begin{array}{l}\text { S2-1. Decide individually and announce the decision } \\
\text { to employees (decide announce) }\end{array}$ \\
\hline $\begin{array}{l}\text { S1-2. A group-based financial incentive } \\
\text { based on the results of the team } \\
\text { (group reward) }\end{array}$ & $\begin{array}{l}\text { S2-2. Decide individually, explain the reason for your } \\
\text { decision to employees and clarify any queries } \\
\text { (decide explain) }\end{array}$ \\
\hline $\begin{array}{l}\text { S1-3. A profit-sharing scheme for all } \\
\text { employees based on the performance } \\
\text { of the entire company (profit sharing) }\end{array}$ & $\begin{array}{l}\text { S2-3. Decide after discussion with the top management } \\
\text { team and announce the decision to employees } \\
\text { (discuss-decide-announce) }\end{array}$ \\
\hline $\begin{array}{l}\text { S1-4. Non-financial individual incentives } \\
\text { (individual non-financial) }\end{array}$ & $\begin{array}{l}\text { S2-4. Decide after discussion with the top management } \\
\text { team, explain the reason to employees and clarify } \\
\text { any queries (discuss-decide-explain) }\end{array}$ \\
\hline $\begin{array}{l}\text { S1-5. Public recognition of the best performing } \\
\text { employees (individual recognition) }\end{array}$ & $\begin{array}{l}\text { S2-5. Consult with employees before reaching a decision. } \\
\text { Listen to their advice, consider it, and then announce } \\
\text { your decision (consult employees) }\end{array}$ \\
\hline $\begin{array}{l}\text { S1-6. Public recognition of the best performing } \\
\text { teams (team recognition) }\end{array}$ & $\begin{array}{l}\text { S2-6. Invite discussion in a meeting with employees to } \\
\text { reach consensus. If consensus is impossible, make } \\
\text { the decision yourself (employee consensus) }\end{array}$ \\
\hline $\begin{array}{l}\text { S1-7. Faster promotion for high performing } \\
\text { individuals (individual promotion) }\end{array}$ & $\begin{array}{l}\text { S2-7. Invite discussion in a meeting with employees and } \\
\text { accept the majority viewpoint as the decision } \\
\text { (meeting majority) }\end{array}$ \\
\hline
\end{tabular}

Scenario 3: Goal-setting

You are a top manager in a company.

What would be your most important priorities?

S3-1.Building and maintaining personal relationships within and outside the company (personal networks)

S3-2. Balancing demands of shareholders and other stakeholders (balance shareholder demands)

S3-3. Managing within the constraints posed by external parties (external constraints)

S3-4. To exercise your power to ensure that employees focus on achieving the goals of the organization (exercise power)

S3-5. Maximizing profit for the shareholders of the company (maximize profit)

S3-6. Coaching/training subordinates to help them reach company objectives (coaching subordinates - objectives)

S3-7. Coaching/training subordinates to ensure their job satisfaction and career development (coaching employees)

S3-8. Keeping your own position safe and reaching your personal goals (personal goals)

\begin{tabular}{|c|c|c|}
\hline Scenario 4: Face-saving & Scenario 5: Conflict-resolving & Scenario 6: Empathizing \\
\hline $\begin{array}{l}\text { You are a manager of company that produces a high- } \\
\text { technology product. You and one of your superiors } \\
\text { are attending a meeting with potential clients. You } \\
\text { have a very good knowledge of the technical aspects } \\
\text { of the product your company sells, because of your } \\
\text { previous experience as a technical engineer. During } \\
\text { the meeting, your superior makes a mistake in } \\
\text { describing the features of the product, because he } \\
\text { doesn't know too much about technical issues. } \\
\text { There is no way to inform your superior of his } \\
\text { mistake during the meeting without clients } \\
\text { noticing it. What would you do? }\end{array}$ & $\begin{array}{l}\text { You are manager of a division manufacturing } \\
\text { high-technology products. In developing new } \\
\text { products, it is important for the sales department } \\
\text { and R\&D department to work together. However, } \\
\text { there are frequent work conflicts between these } \\
\text { two departments. In your opinion what would } \\
\text { be the best way to resolve these conflicts? }\end{array}$ & $\begin{array}{l}\text { You are a manager in a local company. } \\
\text { John, a direct subordinate who has been } \\
\text { with the company for a long time, is } \\
\text { having a difficult time because his wife } \\
\text { suffers from a serious illness. How would } \\
\text { you behave towards him? }\end{array}$ \\
\hline $\begin{array}{l}\text { S4-1. Politely correct your superior in the } \\
\text { meeting (politely correct in meeting). }\end{array}$ & $\begin{array}{l}\text { S5-1. Clarify responsibilities of the two departments } \\
\text { and establish clearer procedures (clarify } \\
\text { responsibilities) }\end{array}$ & $\begin{array}{l}\text { S6-1. Don't talk about it; the illness of a } \\
\text { family member is a private affair } \\
\text { and it is not appropriate to talk } \\
\text { about it at work (private) }\end{array}$ \\
\hline $\begin{array}{l}\text { S4-2. Pretend to be responsible for the mistake } \\
\text { yourself (take responsibility) }\end{array}$ & S5-2. Refer the issue to your superior (refer superior) & $\begin{array}{l}\text { S6-2. Express sympathy and remind John } \\
\text { of the company policies that allow } \\
\text { him to be absent from work for a } \\
\text { certain time to take care of his wife } \\
\text { (express sympathy) }\end{array}$ \\
\hline $\begin{array}{l}\text { S4-3. Mention the correct features in the meeting } \\
\text { without referring to your superior's earlier } \\
\text { description (mention correct features in } \\
\text { meeting) }\end{array}$ & $\begin{array}{l}\text { S5-3. Encourage heads of the two departments } \\
\text { to resolve the conflict (delegate to } \\
\text { department heads) }\end{array}$ & $\begin{array}{l}\text { S6-3. Arrange for your secretary to send } \\
\text { John's wife a card and gift (send gift) }\end{array}$ \\
\hline $\begin{array}{l}\text { S4-4. Say nothing in the meeting, but talk to your } \\
\text { superior afterwards, so that he can decide on } \\
\text { a way to inform the client of his mistake } \\
\text { (talk to superior afterwards) }\end{array}$ & $\begin{array}{l}\text { S5-4. Establish a cross-functional work team } \\
\text { (consisting of sales and R\&D) with } \\
\text { team-level goals (cross-functional team) }\end{array}$ & $\begin{array}{l}\text { S6-4. Ask John's direct colleagues to } \\
\text { support him in any way they can } \\
\text { (colleagues support) }\end{array}$ \\
\hline $\begin{array}{l}\text { S4-5. Say nothing in the meeting, but arrange for } \\
\text { clients to receive full technical information } \\
\text { afterwards. In that way they can verify the } \\
\text { details themselves (inform client afterwards) }\end{array}$ & $\begin{array}{l}\text { S5-5. Involve a conflict mediator and/or an } \\
\text { external consultant to resolve the conflict } \\
\text { (mediator external) }\end{array}$ & $\begin{array}{l}\text { S6-5. Visit John's family to offer moral } \\
\text { support (visit) }\end{array}$ \\
\hline $\begin{array}{l}\text { S4-6. Do nothing. It is not your responsibility to } \\
\text { give the clients technical information } \\
\text { (nothing not responsible) } \\
\text { S4-7. Do nothing. Any action you take would make } \\
\text { your superior lose face (nothing lose face) }\end{array}$ & $\begin{array}{l}\text { S5-6. Ignore the conflict. The issue will resolve } \\
\text { itself (ignore) }\end{array}$ & $\begin{array}{l}\text { S6-6. Arrange for the company to meet } \\
\text { some of the expenses associated } \\
\text { with the illness (pay costs) }\end{array}$ \\
\hline
\end{tabular}

Scenario 5: Conflict-resolving R\&D department to work together. Howe wo departments. In your opinion what would be the best way to resolve these conflicts? responsibilities

$5-2$. Refer the issue to your superior (refer superior)

Encourage heads of the two department to resolve the conflict (delegate to

Establish a cross-functional work team (consisting of sales and R\&D) with Involve a conflict mediator and/or an external consultant to resolve the conflic Ignore the conflict. The issue will resolve itself (ignore) and establish clearer procedures (clarify
Don't talk about it; the illness of a about it at work (private) him to be absent from work for a certain time to take care of his wife press sympathy

3. Arrange for your secretary to send

4. Ask John's direct colleagues to support him in any way they can some of the expenses associated ith the illness (pay costs) support (visit) 
Table 3

Results: leadership scenarios.

\begin{tabular}{|c|c|c|c|c|c|c|c|c|}
\hline \multirow[t]{2}{*}{ Question } & \multicolumn{2}{|c|}{ Language effect } & \multicolumn{4}{|c|}{ Covariates } & \multicolumn{2}{|c|}{ Country effect } \\
\hline & $F_{1}$ & $F_{2}$ & Age & Gender & Work experience & Level of English & Native & English \\
\hline \multicolumn{9}{|l|}{ Rewarding: } \\
\hline S1-1 Individual reward & 0.92 & 1.55 & 0.49 & 0.51 & 0.39 & 0.02 & $3.42^{* * *}$ & $1.66^{*}$ \\
\hline S1-2 Group reward & $6.61^{*}$ & $4.36^{*}$ & 0.16 & 0.38 & $3.87^{*}$ & 0.12 & $2.08^{* *}$ & 1.33 \\
\hline \multicolumn{9}{|l|}{ Decision-making: } \\
\hline S2-4 Discuss-decide-explain & 0.19 & 0.05 & $4.09^{*}$ & 2.80 & 1.47 & 1.49 & $2.17^{* *}$ & 0.83 \\
\hline S2-5 Consult employees & $5.45^{*}$ & $6.07^{*}$ & 3.31 & 2.04 & 0.00 & 0.00 & 1.30 & $2.17^{* *}$ \\
\hline \multicolumn{9}{|l|}{ Goal-setting: } \\
\hline S3-2 Balance shareholder demands & 2.79 & 3.35 & 1.96 & 0.12 & 0.08 & $22.28^{* * *}$ & $4.60^{* * *}$ & $4.45^{* * *}$ \\
\hline S3-6 Coaching subordinates - objectives & 0.30 & 0.15 & 0.00 & 2.81 & 2.96 & 0.17 & $4.15^{* * *}$ & $1.91^{*}$ \\
\hline S3-5 Maximize profit & 1.18 & 0.53 & 2.45 & $30.68^{* * *}$ & 0.35 & 0.05 & $4.34^{* * *}$ & $4.64^{* * *}$ \\
\hline S3-4 Exercise power & 0.07 & 0.00 & 0.00 & 2.08 & 1.32 & $5.45^{*}$ & $9.89^{* * *}$ & $2.72^{* * *}$ \\
\hline \multicolumn{9}{|l|}{ Face-saving: } \\
\hline S4-3 Mention correct features in meeting & 2.94 & $4.22^{*}$ & 2.56 & $4.58^{*}$ & 0.01 & 0.06 & $7.79^{* * *}$ & 1.10 \\
\hline S4-4 Talk to superior afterwards & 0.34 & 0.02 & 3.41 & 2.32 & $4.27^{*}$ & 0.10 & $3.04^{* * *}$ & $2.55^{* *}$ \\
\hline S4-1 Politely correct in meeting & 3.32 & $5.21^{*}$ & $7.18^{* *}$ & $16.50^{* * *}$ & 3.19 & 0.01 & $5.15^{* * *}$ & $3.84^{* * *}$ \\
\hline \multicolumn{9}{|l|}{ Conflict-resolving: } \\
\hline S5-4 Cross-functional team & 3.31 & 3.51 & $5.57^{*}$ & 0.00 & 3.39 & $20.25^{* * *}$ & $4.74^{* * *}$ & $2.45^{* *}$ \\
\hline S5-1 Clarify responsibilities & 0.41 & 0.03 & $9.77^{* * *}$ & 2.51 & 3.42 & 0.03 & $6.71^{* * * *}$ & $2.49^{* *}$ \\
\hline S5-3 Delegate to department heads & $3.90^{*}$ & 2.39 & 3.41 & $6.13^{*}$ & 0.01 & 1.15 & $4.83^{* * *}$ & $2.72^{* * *}$ \\
\hline \multicolumn{9}{|l|}{ Empathizing: } \\
\hline S6-2 Express sympathy & 0.00 & 0.26 & 1.15 & 0.65 & 0.28 & 3.41 & $6.59^{* * *}$ & $6.01^{* * *}$ \\
\hline
\end{tabular}

variables as covariates to control for differences. Our results demonstrate significant country effects for 14 of the 15 scenario alternatives in the local language version and 12 of 15 in the English version (see Table 3).

\section{Discussion}

Our first research question asked whether managers' reactions in a leadership situation context will vary depending on whether it is described in their native language or in English. Our results only displayed partial language effects in two of 15 alternatives pertaining to the six leadership scenarios and additionally in two, after controlling for demographic variables. These findings demonstrate that leadership decisions and reactions depend more on the context of the situation than on the language in which the situation is presented or interpreted. By providing detailed scenarios the situational context is described, leaving less room for ambiguity and interpretation, subsequently minimizing language effects. There seems to be scant support for situational context in the literature. As an example, Ralston, Terpstra, et al. (1995) used a scenario-based questionnaire to gauge whether American expatriate managers in Hong Kong adjusted their influence strategies to suit local cultural norms. Ralston, Terpstra, et al. (1995) found that expatriate managers did not, in fact, change their perceptions about their tactics, even when working in a different cultural setting. The lack of language effects in our results suggests that leaders will react as they would react regardless of the prevailing corporate language. Thus, within countries managers will react similarly in leadership situations regardless of whether they are using their native language or English.

We do not find a cultural accommodation effect when comparing the use of English with the native language. This is perhaps surprising, as the cultural accommodation research has demonstrated language effects on cultural value-laden issues, and that leadership is distinctly culture-dependent. On the other hand, the cultural accommodation literature also provides us with the empirically supported proposition that when there is a lack of cultural accommodation, as in our results, it could be because the respondents have placed value on, and are committed to, the issues under examination (e.g., Bond \& Yang, 1982; Ralston, Terpstra, et al., 1995). In qualitative feedback from the respondents (after completion of the questionnaire), we found an expressed interest in leadership scenarios, and a perceived reality of the situations described, which led us to believe that the leadership scenarios evoked commitment to leadership in respondents. Many of the respondents already worked as managers while undertaking a parttime MBA or executive education. They emphasized in the debriefing that the scenarios and leadership situations described in the questionnaire were familiar to them. But more than this, leadership itself could be at the heart of the matter, infused with primary cultural socialization and not susceptible to the language used.

That there is no strong language effect across countries does not imply similar choices regarding leadership actions in all of the countries in our study. On the contrary, our results revealed significant country effects for almost all scenario alternatives. In our second research question, we specifically address cultural context by querying whether managers' reactions to the studied leadership scenarios differ across countries. The observed country effects demonstrate a strong link between leadership and the respondents' nationalities. Leadership perceptions, preferences, and ideals were strongly associated with national cultural context. This has been convincingly demonstrated in the wealth of crosscultural leadership research, and we may speak with confidence about culture-endorsed leadership (e.g., House, Hanges, Javidan, Dorfman, \& Gupta, 2004; Smith, Peterson, \& Schwartz, 2002; Zander, 1997).

As expected from the cross-cultural leadership literature, there are significant differences in management reactions to the leadership scenarios across countries in our study. The respondents seemingly tap into national culture-endorsed leadership despite the language used, emphasizing the importance not only of situational but also cultural context. Consequently, the presence of country effects, and the lack of language effects across countries, suggests that managers' leadership reactions will vary from one country and cultural context to another, but will not vary depending on the language used. 


\section{Conclusion and managerial relevance}

In addressing the issues of language standardization and instilling a common corporate language, we set out to study whether language influences the ways in which managers respond to different leadership situations. Following Piekkari's (2006) suggestion to treat language as a separate variable, we unveiled that context - not language - matters in our study. Specifically, situational and cultural context contribute to minimizing language effects. Scenarios describing six leadership situations pertaining to Rewarding, Decision-making, Goalsetting, Face-saving, Conflict-resolving, and Empathizing were examined in 17 countries. There were almost no significant differences in managerial reactions when using the native language as opposed to English within countries. Thus, cultural accommodation was not present when managers reacted to these leadership scenarios. Echoing extant research on cross-cultural leadership, where national culture is linked to respondents' nationality, we found significant differences across countries, corroborating the importance of cultural context for leadership and the persistence of cultural variance. These results speak in favor of language standardization, in that instilling English as a common corporate language will not lead to cultural accommodation nor entail losing cultural diversity.

There are limitations to our study. Apart from the apparent limitation of the inclusion of only six leadership scenarios and 17 countries in our study, we have only contrasted one language English - with native language. Other choices of corporate language, such as languages less commonly spoken internationally, could possibly produce different results. However, we believe that the link between leadership and culture is such that respondents will continue to tap into culturally endorsed leadership ideals despite the chosen language.

The use of executive education and MBA participants in an experimental setting outside the actual organization could be viewed as a further limitation. However, our sample consisted of respondents with fairly extensive work experience (nearly 9 years on average). Therefore, rather than being a sterile laboratory experiment isolated from any reality, our leadership scenarios allowed respondents to reflect on their work experience, and, for many who work as managers, the scenarios represented familiar situations.

It is also possible that the respondents' participation in an executive education or MBA program could have had a streamlining effect on their decisions regarding the leadership scenarios (e.g., Tietze, 2004). This can occur for two reasons. First, MBA students and executive education participants may be more similar across countries than the general population. Second, these programs may include similar content and literature, in particular theories and models, often in the original English version. We observed that in most scenarios, across-country differences were smaller for the English version of the questionnaire as opposed to the native language version. Perhaps the use of English had some homogenizing effect across countries. However, almost all acrosscountry differences remained significant. Consequently, as we still find persistent significant differences in preferred leadership scenarios across countries, this strengthens our conclusions for the population as a whole. ${ }^{3}$

That managers' interpretations of and reactions to leadership scenarios may be influenced more by the situational and cultural contexts than by a common corporate language imposed by the organization lends some support to the notion that language standardization may be advantageous while retaining cultural

\footnotetext{
${ }^{3}$ We thank an anonymous reviewer for drawing our attention to this important point.
}

diversity. MNCs that aspire to draw on cultural diversity, will find our results encouraging. However, the lack of cultural accommodation and the presence of cultural variation in leadership approaches will prove language standardization to be an inadequate measure for overriding cultural differences across countries for firms with such ambitions.

Two managerial implications of our findings surface as important for those working in multilingual organizations, and for MNCs opting for English as a corporate language. As describing leadership situations in detail seems to minimize language effects, it is possible that if managers in MNCs are more explicit about leadership practices in use throughout their organization, then the cultural diversity in perspectives, as well as varying ways to lead and organize work, will continue to flourish and enrich firms under the umbrella of language standardization.

Our results also point to the importance of cultural context in limiting language effects. The choice of language will matter less for leadership reactions and actions when individuals share and draw upon the same national cultural frame of reference. For the multilingual and multicultural organization the challenge lies in increasing the overlap between cultural contexts. This may be accomplished through the creation of common platforms across cultural and geographic boundaries by formulating company philosophies and core values; we are yet to receive more in-depth knowledge as to the workings of such measures.

Lastly, a more controversial finding is that recent caveats about using English as a shared language in MNCs may be less salient in certain situations. It appears, based on our results, that the dangers of a standardized language overriding important cultural differences in organizations may be fewer than previously thought. In fact, our results corroborate the view that individuals revert to cultural patterns of reacting to leadership situations when working in a language other than their native language. Subsequently, standardization and contextualization go hand in hand when it comes to leadership.

\section{References}

Bond, M. H., \& Yang, K. S. (1982). Ethnic affirmation versus cross-cultural accommodation: The variable impact of questionnaire language on Chinese bilinguals from Hong Kong. Journal of Cross-Cultural Psychology, 13(2): 169-185.

Botha, E. (1970). The effect of language on values expressed by bilinguals. Journal of Social Psychology, 80: 143-145.

Brislin, R. W. (1980). Translation and content analysis of oral and written material. In H. C. Triandis \& J. W. Berry (Eds.), Handbook of cross-cultural psychology 1 (pp. 389444). Boston, NY: Allyn and Bacon.

Candell, G. I., \& Hulin, C. I. (1986). Cross-language and cross-cultural comparisons in scale translations. Journal of Cross-Cultural Psychology, 17(4): 417-440.

Charles, M., \& Marschan-Piekkari, R. (2002). Language training for enhanced horizontal communication: A challenge for MNCs. Business Communication Quarterly, 65(2): $9-29$.

Dhir, K. S., \& Goke-Pariola, A. (2002). The case for language policies in multinational corporations. Corporate Communications: An International Journal, 7(4): 241251.

Earle, M. J. (1969). A cross-cultural and cross-language comparison of dogmatism scores. Journal of Social Psychology, 79: 19-24.

Feely, A. J., \& Harzing, A. W. K. (2003). Language management in multinational companies. Cross-Cultural Management, 10(2): 37-52.

Fredriksson, R., Barner-Rasmussen, W., \& Piekkari, R. (2006). The multinational corporation as a multilingual organization: The notion of a common corporate language. Corporate Communication: An International Journal, 11(4): 406-423.

Green, R. T., \& White, P. D. (1976). Methodological considerations in cross-national consumer research. Journal of International Business Studies, 7(2): 81-87.

Griffith, D. A. (2002). The role of communication competencies in international business relationship development. Journal of World Business, 37: 256-265.

Harzing, A. W. K. \& 23 collaborators. (2005). Does the use of English-language questionnaires in cross-national research obscure national differences? International Journal of Cross Cultural Management, 5(2): 213-224.

Harzing, A. W. K., \& Feely, A. J. (2008). The language barrier and its implications for HQsubsidiary relationships. Cross Cultural Management: An International Journal, 15(1): 49-60.

Harzing, A. W. K., Maznevski, M. L. \& 10 collaborators. (2002). The interaction between language and culture: A test of the cultural accommodation hypothesis in seven countries. Language and Intercultural Communication, 2(2): 120139. 
House, R. J., Hanges, P. J., Javidan, M., Dorfman, P. W., \& Gupta, V. (2004). Culture, leadership and organizations: The GLOBE study of 62 societies. Thousand Oaks, CA: Sage.

Hulin, C. I., Drasgow, F., \& Komocar, J. (1982). Applications of item response theory to analysis of attitude scale translations. Journal of Applied Psychology, 67(6): 818-825.

Human Resource Management International Digest. (2007). Siemens speaks several languages - despite what the management says: Multinational corporation remains a multilingual organization. Human Resource Management International Digest, 15(6): 16-17.

Janssens, M., Lambert, J., \& Steyaert, C. (2004). Developing language strategies for international companies: The contribution of translation studies. Journal of World Business, 39: 414-430.

Katerberg, R., Smith, F. J., \& Hoy, S. (1977). Language, time and person effects on attitude scale translations. Journal of Applied Psychology, 62(4): 385-391.

Louhiala-Salminen, L., Charles, M., \& Kankaanranta, A. (2005). English as a lingua franca in Nordic corporate mergers: Two case companies. English for Specific Purposes, 24: 401-421.

Luo, Y., \& Shenkar, O. (2006). The multinational corporation as a multilingual community: Language and organization in a global context. Journal of International Business Studies, 37: 321-339.

Maclean, D. (2006). Beyond English: Transnational corporations and the strategic management of language in a complex multilingual business environment. Management Decision, 44(10): 1377-1390.

Marschan, R., Welch, L. S., \& Welch, D. E. (1997). Language: The forgotten factor in multinational management. European Management Journal, 15(5): 591-598.

Marschan-Piekkari, R., Welch, D. E., \& Welch, L. S. (1999a). Adopting a common corporate language: IHRM implications. International Journal of Human Resource Management, 10(3): 377-390.

Marschan-Piekkari, R., Welch, D. E., \& Welch, L. S. (1999b). In the shadow: The impact of language on structure, power and communication in the multinational. International Business Review, 8: 421-440.

Nasser, R. (2005). A method for social scientists to adapt instruments from one culture to another: The case of the Job Descriptive Index. Journal of Social Sciences, 1(4): 232-237.

Osland, J. S. (1995). The adventures of working abroad. San Fransciso, CA: Jossey-Bass.

Piekkari, R. (2006). Language effects in multinational corporations: A review from an international human resource management perspective. In G. K. Stahl \& I. Björk- man (Eds.), Handbook of research in international human resource management (pp. 536-550). Cheltenham, UK: Edward Elgar.

Piekkari, R., Vaara, E., Tienari, J., \& Säntti, R. (2005). Integration or disintegration? Human resource implications of a common corporate language decision in a cross-border merger. International Journal of Human Resource Management, 16(3): 330-344.

Politzer, G. (1991). Comparison of deductive abilities across language. Journal of CrossCultural Psychology, 22(3): 389-402.

Ralston, D. A., Cunniff, M. K., \& Gustafson, D. J. (1995). Cultural accommodation: The effect of language on the responses of bilingual Hong Kong Chinese managers. Journal of Cross-Cultural Psychology, 26(6): 714-727.

Ralston, D. A., Terpstra, R. H., Cunniff, M. K., \& Gustafson, D. A. (1995). Do expatriate managers change their behaviors to fit a foreign culture? A study of American expatriates' strategies of upward influence. Management International Review, 35(1): 109-122.

Smith, P. B., Peterson, M. F., \& Schwartz, S. H. (2002). Cultural values, sources of guidance, and their relevance to managerial behavior: A 47-nation study. Journal of Cross-Cultural Psychology, 33(2): 188-208.

Tietze, S. (2004). Spreading the management gospel - in English. Language and Intercultural Communication, 4(3): 176-189.

Tyson, G. A., Doctor, E. A., \& Mentis, M. (1988). A psycholinguistic perspective on bilinguals' discrepant questionnaire response. Journal of Cross-Cultural Psychology, 19(4): 413-426.

Van de Vijver, F., \& Leung, K. (1997). Methods and data analysis for cross-cultural research. Thousand Oaks, CA: Sage.

Watkins, D. \& Gerong, A. (1999). Language of response and the spontaneous selfconcept: A test of the cultural accommodation hypothesis. Journal of Cross-Cultural Psychology, 30(1): 115-121.

Welch, D. E., \& Welch, L. S. (2008). The importance of language in international knowledge transfer. Management International Review, 48(3): 339-360.

Whorf, B. L. (1956). Language, thought and reality. New York: Wiley.

Yang, K. S., \& Bond, M. H. (1980). Ethnic affirmation by Chinese bilinguals. Journal of Cross-Cultural Psychology, 11: 411-425.

Zander, L. (1997). The License to lead: An 18 country study of the relationship between employees' preferences regarding interpersonal leadership and national culture. Published Ph. D. dissertation, Stockholm: Institute of International Business, Stockholm School of Economics. 